\title{
The Outcome of Radiofrequency Kyphoplasty in the Treatment of Vertebral Compression Fractures in Osteoporotic Patients
}

\author{
Ramy Hegazy ${ }^{1}$, Hesham El-Mowafi ${ }^{1}$, Mahmood Hadhood ${ }^{1}$, \\ Yasser Hannout ${ }^{1}$, Yasser Allam ${ }^{2}$, Jeorg Silbermann ${ }^{3}$ \\ ${ }^{I}$ Department of Orthopaedic Surgery, Menoufia Faculty of Medicine Hospital, Menoufia University College of Medicine, Shebin el-kom, Egypt \\ ${ }^{2}$ Spine Unit, Al Hadra University Hospital, Alexandria University, Alexandria, Egypt \\ ${ }^{3}$ Spine Unit, Wald Klinikum Gera, Gera, Germany
}

Study Design: Retrospective study.

Purpose: The study aims to assess the effectiveness and safety of radiofrequency (RF) kyphoplasty in the treatment of vertebral compression fractures (VCFs) in osteoporotic patients.

Overview of Literature: Vertebroplasty and balloon kyphoplasty are established procedures for the treatment of osteoporotic VCFs. However, RF kyphoplasty is a new method which controls cement viscosity.

Methods: We reviewed the results of 41 consecutive patients with 23 thoracic and 38 lumbar VCFs who underwent RF kyphoplasty. The study population included 14 males (34\%) and 27 females (66\%). The mean patients age was 78 years (range, 51-89 years), and the follow-up period was 1 year. Clinical and radiographic analyses were performed during follow-up at 6 weeks, 6 months, and 1 year. All patients were assessed clinically pre- and postoperative using the Visual Analog Scale (VAS) and Oswestry Disability Index (ODI). Radiological assessment with X-ray in two views preoperatively, postoperatively, and during follow-up visits.

Results: The mean preoperative VAS was 8.7 (range, 5-10; standard deviation [SD], 1.2). Postoperatively, VAS decreased by 3.3 (range, $2-5 ;$ SD, 0.9). At the end of the follow-up, VAS decreased by 1.22 (range, $0-7 ;$ SD, 1.6). The mean preoperative ODI score was 85.9, decreasing to 9.6 postoperatively and improving to 18.4 during the 1 -year follow-up. The mean local kyphotic angle was $9.04^{\circ}$ before the procedure and decreased by a mean of $6.16^{\circ}$ after the operation and at the end of the follow-up. The mean increase in vertebral body height was $3.3 \mathrm{~mm}$ postoperatively and after 1 -year follow-up. The rate of cement leakage was $8 \%$ (five out of 61 levels of fracture).

Conclusions: RF kyphoplasty is a safe and effective augmentation technique with an advantage of controlling the cement viscosity to minimize the risk of cement leakage. It also shortens operation time.

Keywords: Vertebral fractures; Osteoporosis; Radiofrequency; Kyphoplasty

Received Jun 1, 2018; Revised Aug 21, 2018; Accepted Sep 10, 2018

Corresponding author: Ramy Hegazy

Department of Orthopaedic Surgery, Menoufia University College of Medicine, Yassin Abdel Ghaffar St. from Gamal Abdel Nasser St., Shebin el-kom, Menoufia, 32511, Egypt

Tel: +20-482222731, Fax:+20-482317508, E-mail: ramyhegazy31@gmail.com 


\section{Introduction}

Osteoporosis is the most common cause of vertebral compression fractures (VCFs) which result in debilitating back pain and negatively impact the patient's quality of life [1]. Conservative treatment of symptomatic VCFs consists of medical therapy, which includes analgesics, anti-osteoporotic drugs, bed rest for a limited time, external bracing, physiotherapy, and rehabilitation. These treatments are only partially effective as they take a longer time and do not prevent further kyphotic deformity [2].

Vertebroplasty and kyphoplasty are minimally invasive percutaneous approaches developed for the treatment of symptomatic VCFs. It is well established that more than $90 \%$ of patients with osteoporotic fractures will experience rapid and significant pain relief from these procedures with improved functionality and quality of life. Although not well established, the most likely mechanism for pain relief after kyphoplasty (even without significant restoration of vertebral body height) appears to be mechanical stabilization of the vertebral body $[3,4]$.

The main risk of these minimally invasive techniques is leakage of polymethyl methacrylate (PMMA) into the venous system, which is reported in large prospective randomized trials to be as high as $72 \%$ in vertebroplasty and $27 \%$ in balloon kyphoplasty. Most leakages are asymptomatic but may result in pulmonary embolism. Leakage through the fracture into the spinal canal or neural foramina may lead to neurologic disorders or other complications like local or systemic reactions to cement or infection [5-7].

Radiofrequency (RF) kyphoplasty is a new method for VCF treatment, approved in the United States in 2007 and in Germany in 2009. Its principle depends on the ex vivo transformation of PMMA cement by RF into a semisolid mass of ultrahigh viscosity. This inactivated cement can be applied in controlled fashion for up to 35 minutes, while its properties remain constant without destroying the cancellous bone that is still existing [8].

In this study, we assessed the effectiveness of a new method of RF kyphoplasty and its benefits over old methods for the treatment of VCFs.

\section{Materials and Methods}

\section{Materials}

This is a prospective study of 41 consecutive patients with 23 thoracic and 38 lumbar VCFs who underwent RF kyphoplasty. The study population included 14 males (34\%) and 27 females $(66 \%)$ with a mean age of 78 years (range, 51-89 years). The follow-up period was 1 year. Informed consent was a prerequisite for all patients before to be involved in our research. The research was approved by Menoufia University College of Medicine Institutional Review Board.

\section{1) Inclusion criteria}

All patients had one or more painful thoracic or lumbar VCFs due to primary or secondary osteoporosis, bone hemangioma, multiple myelomas, bone metastases, failed conservative treatment for at least 2-3 weeks, or radiologically confirmed fresh compression fracture (AO type A1). Magnetic resonance imaging (MRI) showed edema and X-ray/computed tomography (CT) scan, proven fracture not older than 3 months.

\section{2) Exclusion criteria}

Coagulopathy, infection, evidence of radiculopathy from a retropulsed bone, bone cement allergy, unstable fractures (AO type A2.1, A3.1), B and C, vertebral deformation (e.g., vertebra plana), and pregnancy.

\section{3) Preoperative clinical assessment}

Patients were asked to quantify their pain on a Visual Analog Scale (VAS) and Oswestry Disability Index (ODI).

Radiological evaluations include plain radiography, MRI of the spine, and multi-slice CT scan to assess continuity of the posterior vertebral wall and to exclude other causes of pain, such as a herniated nucleus pulposus or adjacent tumor mass. On the lateral X-ray, local kyphotic angle and mean vertebral height were measured [9].

\section{The procedure}

All procedures were performed with patients under general anesthesia in prone position using two fluoroscopic image guidance and with an unipedicular transpedicular approach. The orientation of the C-arm beam is of critical importance. The anteroposterior (AP) images must 


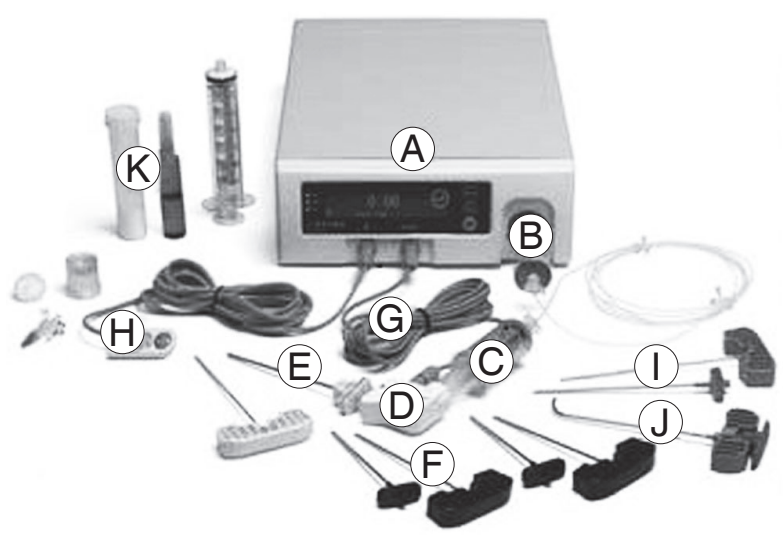

Fig. 1. Radifrequency device and application system. (A) Multiplex controller; (B) hydraulic assembly; (C) master syringe; (D) activation element; (E) locking delivery cannula; (F) StabiliT introducer-working cannula and stylet; $(\mathbf{G})$ activation element cable; $(\mathbf{H})$ hand switch cable; (I) straight line osteotome; (J) PowerCurve navigating osteotome; and (K) StabiliT ER2 bone cement.

be true AP images of each pedicle. The spinous process should be in the midline of the vertebral body, equally spaced between both pedicles. The superior and inferior endplates should be parallel, and the pedicles should be appropriately located at the caudal end of the ascending articular process. On the lateral view, the superior endplate should appear as one line, and the pedicles should overlap and thus appear as one. The pedicle of interest was localized utilizing the AP fluoroscopic image. Disinfection and surgical draping were performed, and the skin was incised just lateral to the pedicle.

The StabiliT introducer was inserted into the posterior one third of the vertebral body (Fig. 1). The StraightLine cement staging osteotome was then inserted through an introducer-working cannula into the anterior one third of the vertebral body to create an initial cavity; the osteotome was also optionally used to collect a biopsy specimen. The PowerCurve navigating osteotome was then utilized to create a cavity within the center of the vertebral body and superiorly and inferiorly directed pathways permitting access to other areas of the vertebral body through unipedicular approach, enabling targeted vertebral access across the midline via a unipedicular approach (Fig. 2).

Before the actual application of cement, the so-called MultiPlex controller (Fig.1), a RF generator with a hydraulic regulator, is switched on. The activation element, cable, and a special hydraulic were connected to the controller. A cement cartridge was filled with liquid monomer, fixed to the hydraulic assembly, and connected to the activation element. After removing the introducer stylet,

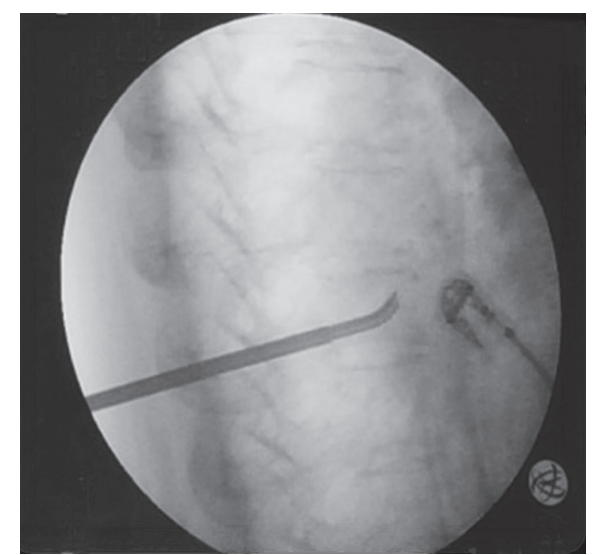

Fig. 2. Intraoperative X-ray. PowerCurve navigating osteotome utilized to create a cavity within the center of the vertebral body as well as superiorly and inferiorly directed pathways permitting access to other areas of the vertebral body through unipedicular approach.

the locking delivery cannula was fixed to the activation element and introduced into the working cannula such that the end of the delivery cannula is located in the prepared intravertebral space created in the anterior third of the vertebral body and ultrahigh viscosity bone cement was delivered into the osteotome created cavity.

As the StabiliT ER2 bone cement fills the cavity, it expands on top of itself, applying a load across the surface area of the cavity, driving potential height restoration of the fracture. It is the cement viscosity that drives the potential for height restoration. The hand switch cable, which starts and stops the flow of ultrahigh viscosity cement, allows the operator to remain up to $100 \mathrm{~cm}$ from the patient's side during cement delivery and provided controlled cement delivery with the added advantage of potentially reducing radiation exposure. Once cement delivery is complete, the delivery cannula is removed, and stylet is reinserted prior to instrument removal.

\section{Evaluation}

1) Postoperative assessment

Patients were assessed for the improvement of back pain and function by VAS and ODI and for focal neurologic deficit.

2) Postsurgical imaging follow-up

All patients were imaged with postoperative radiography in AP and lateral view to document the cement location and to measure the mean vertebral height and local 
Table 1. Data of the treated patients: number, age of the patient, sex, level treated, (preoperative and postoperative symptoms), and complications

\begin{tabular}{|c|c|c|c|c|c|c|c|c|c|c|}
\hline \multirow{2}{*}{ No. } & \multirow{2}{*}{$\begin{array}{c}\text { Age } \\
(y r)\end{array}$} & \multirow{2}{*}{ Sex } & \multirow{2}{*}{$\begin{array}{l}\text { No. of } \\
\text { level }\end{array}$} & \multirow{2}{*}{ Level } & \multirow{2}{*}{$\begin{array}{c}\text { Time of } \\
\text { operation }\end{array}$} & \multicolumn{2}{|c|}{ Visual Analog Scale } & \multicolumn{2}{|c|}{ Oswestry Disability Index } & \multirow{2}{*}{$\begin{array}{l}\text { Cement } \\
\text { leakage }\end{array}$} \\
\hline & & & & & & Preoperative & Postoperative & Preoperative & Postoperative & \\
\hline 1 & 87 & $\mathrm{~F}$ & 1 & Th12 & 25 & 7 & 3 & 76 & 22 & Type C \\
\hline 2 & 80 & $\mathrm{~F}$ & 1 & $\mathrm{~L} 5$ & 23 & 9 & 2 & 98 & 6 & No \\
\hline 3 & 75 & $\mathrm{~F}$ & 1 & Th12 & 27 & 8 & 3 & 88 & 18 & No \\
\hline 4 & 89 & M & 3 & $\lfloor 3,4,5$ & 55 & 10 & 2 & 100 & 10 & No \\
\hline 5 & 81 & M & 2 & $\mathrm{~L} 2,3$ & 38 & 10 & 3 & 100 & 0 & No \\
\hline 6 & 79 & $\mathrm{~F}$ & 1 & Th12 & 28 & 9 & 4 & 100 & 26 & No \\
\hline 7 & 75 & M & 2 & $\lfloor 4,5$ & 38 & 8 & 4 & 88 & 8 & No \\
\hline 8 & 62 & M & 3 & Th7, 8, L1 & 55 & 10 & 5 & 90 & 18 & No \\
\hline 9 & 77 & $\mathrm{~F}$ & 2 & Th8, 9 & 40 & 10 & 4 & 100 & 28 & No \\
\hline 10 & 79 & M & 1 & Th7 & 22 & 8 & 3 & 78 & 12 & No \\
\hline 11 & 77 & M & 3 & $L 1,2,4$ & 58 & 10 & 4 & 92 & 8 & Type S \\
\hline 12 & 86 & $\mathrm{~F}$ & 1 & Th6 & 22 & 8 & 3 & 82 & 4 & No \\
\hline 13 & 75 & $\mathrm{~F}$ & 1 & Th5 & 20 & 6 & 2 & 66 & 4 & Type B \\
\hline 14 & 87 & $\mathrm{~F}$ & 1 & 13 & 23 & 9 & 3 & 92 & 0 & No \\
\hline 15 & 60 & M & 1 & Th8 & 25 & 5 & 2 & 60 & 0 & No \\
\hline 16 & 88 & $\mathrm{~F}$ & 1 & Th11 & 26 & 7 & 2 & 76 & 6 & No \\
\hline 17 & 85 & M & 1 & L3 & 23 & 9 & 3 & 96 & 18 & No \\
\hline 18 & 75 & $\mathrm{~F}$ & 1 & Th11 & 28 & 8 & 3 & 86 & 14 & No \\
\hline 19 & 81 & $\mathrm{~F}$ & 1 & Th12 & 28 & 9 & 3 & 92 & 2 & No \\
\hline 20 & 78 & M & 4 & Th11, L3, 4, 5 & 68 & 10 & 4 & 96 & 42 & Type B \\
\hline 21 & 77 & M & 1 & $\mathrm{~L} 2$ & 22 & 8 & 3 & 74 & 12 & No \\
\hline 22 & 80 & M & 1 & L1 & 25 & 9 & 4 & 92 & 2 & No \\
\hline 23 & 76 & $\mathrm{~F}$ & 4 & $\lfloor 4,3,2,1$ & 70 & 10 & 4 & 98 & 16 & No \\
\hline 24 & 66 & $\mathrm{~F}$ & 3 & Th12, L1, 4 & 55 & 10 & 5 & 100 & 0 & No \\
\hline 25 & 82 & $\mathrm{~F}$ & 1 & Th10 & 22 & 8 & 4 & 88 & 4 & No \\
\hline 26 & 51 & M & 3 & Th12, L1, 2 & 54 & 9 & 3 & 92 & 18 & No \\
\hline 27 & 88 & $\mathrm{~F}$ & 1 & $\mathrm{~L} 2$ & 24 & 10 & 4 & 98 & 4 & No \\
\hline 28 & 70 & $\mathrm{~F}$ & 1 & L1 & 26 & 7 & 2 & 76 & 0 & No \\
\hline 29 & 84 & $\mathrm{~F}$ & 1 & $\mathrm{~L} 1$ & 23 & 8 & 2 & 82 & 4 & Type S \\
\hline 30 & 85 & $\mathrm{~F}$ & 1 & L1 & 26 & 9 & 3 & 88 & 22 & No \\
\hline 31 & 73 & M & 1 & $\mathrm{~L} 1$ & 27 & 8 & 3 & 74 & 8 & No \\
\hline 32 & 85 & $\mathrm{~F}$ & 1 & L1 & 30 & 10 & 4 & 92 & 4 & No \\
\hline 33 & 78 & M & 1 & Th12 & 20 & 10 & 4 & 100 & 14 & No \\
\hline 34 & 61 & $\mathrm{~F}$ & 2 & Th12, L1 & 39 & 9 & 3 & 68 & 2 & No \\
\hline 35 & 75 & $\mathrm{~F}$ & 1 & L1 & 23 & 9 & 4 & 74 & 8 & No \\
\hline 36 & 85 & $\mathrm{~F}$ & 1 & L1 & 24 & 8 & 3 & 66 & 2 & No \\
\hline 37 & 87 & $\mathrm{~F}$ & 1 & Th12 & 22 & 10 & 4 & 82 & 4 & No \\
\hline 38 & 89 & $\mathrm{~F}$ & 1 & $\mathrm{~L} 2$ & 19 & 10 & 5 & 94 & 8 & No \\
\hline 39 & 80 & $\mathrm{~F}$ & 1 & Th12 & 26 & 9 & 4 & 72 & 6 & No \\
\hline 40 & 84 & $\mathrm{~F}$ & 1 & Th12 & 28 & 10 & 5 & 84 & 0 & No \\
\hline 41 & 76 & $F$ & 1 & L4 & 18 & 8 & 2 & 72 & 12 & No \\
\hline
\end{tabular}

$\mathrm{F}$, female; $\mathrm{M}$, male. 
kyphotic angle. Leaks of the cement were classified into three types: those via the basivertebral vein (type B), via the segmental vein (type $S$ ), and through a cortical defect (type C) [10].

Clinical and radiographic analyses were performed during follow-up at 6 weeks, 6 months, and 1 year.

\section{Statistical analysis}

Data were evaluated using the SPSS statistical program packet ver. 16.0 (SPSS Inc., Chicago, IL, USA). The following statistical measures were used to demonstrate values: number, mean, standard deviation (SD), minimum, and maximum. As a nonparametric test for paired random samples, the Wilcoxon rank sum test and paired $t$-test were used to evaluate the results. The level of significance was set to $p<0.005$.

\section{Results}

In 30 patients $(73 \%)$, one level fracture was treated, and the mean operating time was 24 minutes (range, 18-30 minutes). In four patients (10\%), two levels were augmented and required a mean operating time of 38 minutes (range, 38-40 minutes). In five patients (12\%), three levels were treated requiring an operating time of 55 minutes (range, 54-58 minutes). In two patients (5\%), four levels were treated, and the mean operating time was $69 \mathrm{~min}$ utes (range, 68-70 minutes). The maximum number of fractures was in the thoracolumbar junction (23 patients, 56\%), thoracic fractures (Th5-Th9) constituted 15\% (six patients), and lumbar fractures (L2-L5) constituted 29\% (12 patients). The main level affected was L1 followed by Th12.

There were 10 patients (24\%) who had secondary osteoporosis caused by long-term corticosteroid therapy. The remainder 31 (76\%) were assumed to have primary osteoporosis. All patients were mobilized within the first 24 hours after surgery. Thirty-one patients (76\%) were hospitalized for 1-3 days. Due to additional injuries, 10 patients (24\%) stayed for a maximum of 10 days. The mean preoperative pain score on VAS was 8.7 (range, 5-10; $\mathrm{SD}, 1.2$ ). Postoperatively, the mean score was 3.3 (range, $2-5$; SD, 0.9 ); VAS 6 months postoperatively, a mean score of 1.07 (range, $0-5$; SD, 0.9); and VAS 12 months postoperatively, a mean score of 1.22 (range, $0-7 ; \mathrm{SD}, 1.6$ ). Thus, significant pain relief $(p<0.005)$ was achieved in all three consecutive intervals of follow-up. The mean preoperative ODI score was 85.9 , decreasing to 9.6 postoperatively and improving at 10.1 and 18.4 at 6 months and 1-year followup, respectively. These results are depicted in Table 1.

The mean local kyphotic angle was $9.04^{\circ}$ before the procedure and decreased by a mean of $6.16^{\circ}$ after the operation, as well as at 6 months and 1-year follow-up $(p<0.005)$. In 23 fractures $(37.7 \%)$, the reduction was achieved by less than $2^{\circ}$, while the reduction of $2^{\circ}-5^{\circ}$ occurred in 25 fractures (40.98\%). In 13 fractures (21.3\%), a reduction of $>5^{\circ}-10^{\circ}$ was achieved. The mean vertebral height was $19.16 \mathrm{~mm}$ preoperatively, increasing by a mean of $22.50 \mathrm{~mm}$ postoperatively and remaining unchanged at 6 months and 1-year follow-up $(p<0.005)$. Results are illustrated in Table 2.

Note that in 25 fractures (41.0\%), the reduction was achieved by less than $2 \mathrm{~mm}$, while a reduction of 2-5 $\mathrm{mm}$ was achieved in 21 fractures (34.4\%). In 13 fractures (21.3\%) and two fractures (3.3\%), reductions of $>5-10$ $\mathrm{mm}$ and $>10 \mathrm{~mm}$ were achieved, respectively.

Postoperative complications are as follows. Cement leakage occurred in five (8\%) of 61 augmented vertebral bodies. Type $S$ (via the segmental vein) leakage occurred in two cases. Type B (via the basivertebral vein) leakage occurred in two cases. We observed only one case of type $\mathrm{C}$ leakage (through a cortical defect). No cement leakage required revision, and no other complication was detected.

\section{Discussion}

VCFs are the most frequent fractures associated with osteoporosis. At 5 years after diagnosis, the estimated survival rate is reported to be $61 \%$; clinically diagnosed vertebral fractures are rarely fatal, and the reduced survival rate is related to comorbid conditions [11].

RF kyphoplasty is a novel vertebral augmentation procedure that consists of non-balloon, bone-sparing cavity creation and targeted delivery of an ultrahigh viscosity cement after activation using RF energy.

The bone cement viscosity and polymerization of energy-responsive bone cement are controlled by a low-power bipolar RF warming source that warms the bone cement to provide consistent ultrahigh viscosity properties over an extended working time. The ultrahigh viscosity cement allows for superior interdigitation with cancellous bone without a destroying effect, and the risk of cement leakage 
Table 2. Data of the treated vertebral fractures: preoperative and postoperative vertebral height and vertebral kyphosis, reduction achieved, and correction in percent

\begin{tabular}{|c|c|c|c|c|c|c|c|c|}
\hline \multirow{2}{*}{ No. } & \multicolumn{2}{|c|}{ Mean vertebral height (mm) } & \multirow{2}{*}{ Reduction } & \multirow{2}{*}{$\%$} & \multicolumn{2}{|c|}{ Kyphosis angel $\left({ }^{\circ}\right)$} & \multirow{2}{*}{ Reduction } & \multirow{2}{*}{$\%$} \\
\hline & Preoperative & Postoperative & & & Preoperative & Postoperative & & \\
\hline 1 & 14.7 & 17.0 & 2.3 & 15.6 & 4.70 & 4.3 & 0.4 & 8.5 \\
\hline 2 & 13.7 & 15.9 & 2.2 & 16.1 & 21.9 & 12.8 & 9.1 & 41.6 \\
\hline 3 & 12.7 & 21.9 & 9.2 & 72.4 & 7.0 & 3.0 & 4.0 & 57.1 \\
\hline 4 & 26.0 & 28.1 & 2.1 & 8.1 & 6.3 & 5.3 & 1.0 & 15.9 \\
\hline 5 & 30.6 & 31.9 & 1.3 & 4.2 & 5.7 & 2.6 & 3.1 & 54.4 \\
\hline 6 & 30.4 & 32.1 & 1.7 & 5.6 & 6.4 & 4.9 & 1.5 & 23.4 \\
\hline 7 & 13.0 & 23.9 & 10.9 & 83.8 & 3.2 & 0.4 & 2.8 & 87.5 \\
\hline 8 & 15.0 & 23.5 & 8.5 & 56.7 & 9.1 & 3.0 & 6.1 & 67.0 \\
\hline 9 & 16.0 & 24.4 & 8.4 & 52.5 & 14.5 & 4.8 & 9.7 & 66.9 \\
\hline 10 & 18.3 & 28.2 & 9.9 & 54.1 & 5.5 & 4.6 & 0.9 & 16.4 \\
\hline 11 & 10.5 & 18.8 & 8.3 & 79.0 & 3.8 & 1.2 & 2.6 & 68.4 \\
\hline 12 & 12.4 & 12.9 & 0.5 & 4.0 & 14.2 & 12.9 & 1.3 & 9.2 \\
\hline 13 & 13.8 & 16.3 & 2.5 & 18.1 & 9.4 & 4.3 & 5.1 & 54.3 \\
\hline 14 & 15.3 & 28.6 & 13.3 & 86.9 & 8.1 & 5.9 & 2.2 & 27.2 \\
\hline 15 & 16.2 & 21.7 & 5.5 & 34.0 & 13.3 & 10.8 & 2.5 & 18.8 \\
\hline 16 & 18.7 & 19.4 & 0.7 & 3.7 & 10.3 & 10.0 & 0.3 & 2.9 \\
\hline 17 & 19.0 & 19.1 & 0.1 & 0.5 & 10.4 & 6.9 & 3.5 & 33.7 \\
\hline 18 & 16.1 & 21.3 & 5.2 & 32.3 & 10.8 & 4.1 & 6.7 & 62.0 \\
\hline 19 & 26.7 & 27.5 & 0.8 & 3.0 & 5.2 & 2.1 & 3.1 & 59.6 \\
\hline 20 & 26.0 & 27.0 & 1.0 & 3.8 & 3.1 & 2.3 & 0.8 & 25.8 \\
\hline 21 & 10.1 & 12.2 & 2.1 & 20.8 & 14.1 & 11.4 & 2.7 & 19.1 \\
\hline 22 & 12.9 & 13.6 & 0.7 & 5.4 & 13.0 & 6.7 & 6.3 & 48.5 \\
\hline 23 & 21.9 & 23.1 & 1.2 & 5.5 & 3.2 & 2.9 & 0.3 & 9.4 \\
\hline 24 & 18.0 & 18.7 & 0.7 & 3.9 & 15.6 & 12.3 & 3.3 & 21.2 \\
\hline 25 & 15.0 & 20.2 & 5.2 & 34.7 & 6.3 & 3.3 & 3.0 & 47.6 \\
\hline 26 & 25.4 & 27.1 & 1.7 & 6.7 & 0.6 & 0.4 & 0.2 & 33.3 \\
\hline 27 & 22.2 & 25.2 & 3.0 & 13.5 & 10.8 & 4.5 & 6.3 & 58.8 \\
\hline 28 & 20.3 & 22.3 & 2.0 & 9.9 & 13.9 & 13.0 & 0.9 & 6.5 \\
\hline 29 & 16.5 & 17.2 & 0.7 & 4.2 & 9.7 & 4.0 & 5.7 & 58.3 \\
\hline 30 & 25.5 & 25.7 & 0.2 & 0.8 & 3.1 & 2.0 & 1.1 & 35.5 \\
\hline 31 & 28.2 & 28.4 & 0.2 & 0.7 & 2.0 & 1.8 & 0.2 & 10.0 \\
\hline 32 & 28.6 & 30.0 & 1.4 & 4.9 & 3.3 & 3.0 & 0.3 & 9.1 \\
\hline 33 & 28.5 & 30.8 & 2.3 & 8.1 & 0.9 & 0.2 & 0.7 & 77.8 \\
\hline 34 & 21.5 & 25.6 & 4.1 & 19.1 & 13.7 & 11.4 & 2.3 & 16.8 \\
\hline 35 & 19.1 & 20.2 & 1.1 & 5.8 & 8.3 & 6.4 & 1.9 & 22.9 \\
\hline 36 & 19.4 & 21.1 & 1.7 & 8.8 & 2.4 & 2.0 & 0.4 & 16.7 \\
\hline 37 & 18.4 & 20.9 & 2.5 & 13.6 & 6.0 & 4.9 & 1.1 & 18.3 \\
\hline 38 & 20.8 & 21.5 & 0.7 & 3.4 & 9.1 & 7.8 & 1.3 & 14.3 \\
\hline 39 & 15.2 & 16.7 & 1.5 & 9.9 & 12.6 & 10.4 & 2.2 & 17.5 \\
\hline
\end{tabular}


Table 2. Continued

\begin{tabular}{|c|c|c|c|c|c|c|c|c|}
\hline \multirow{2}{*}{ No. } & \multicolumn{2}{|c|}{ Mean vertebral height (mm) } & \multirow{2}{*}{ Reduction } & \multirow{2}{*}{$\%$} & \multicolumn{2}{|c|}{ Kyphosis angel $\left({ }^{\circ}\right)$} & \multirow{2}{*}{ Reduction } & \multirow{2}{*}{$\%$} \\
\hline & Preoperative & Postoperative & & & Preoperative & Postoperative & & \\
\hline 40 & 18.2 & 18.9 & 0.7 & 3.8 & 7.1 & 6.5 & 0.6 & 8.5 \\
\hline 41 & 21.3 & 23.3 & 2.0 & 9.4 & 2.0 & 1.3 & 0.7 & 35.0 \\
\hline 42 & 15.8 & 19.6 & 3.8 & 24.1 & 11.0 & 4.4 & 6.6 & 60.0 \\
\hline 43 & 33.0 & 35.3 & 2.3 & 7.0 & 7.6 & 5.6 & 2.0 & 26.3 \\
\hline 44 & 28.8 & 30.6 & 1.8 & 6.3 & 6.2 & 4.4 & 1.8 & 29.0 \\
\hline 45 & 26.3 & 26.7 & 0.4 & 1.5 & 7.5 & 5.5 & 2.0 & 26.7 \\
\hline 46 & 18.7 & 23.4 & 4.7 & 25.1 & 17.5 & 13.6 & 3.9 & 22.3 \\
\hline 47 & 14.2 & 23.5 & 9.3 & 65.5 & 10.2 & 7.4 & 2.8 & 27.5 \\
\hline 48 & 17.7 & 17.8 & 0.1 & 0.6 & 13.0 & 10.5 & 2.5 & 19.2 \\
\hline 49 & 20.2 & 21.0 & 0.8 & 4.0 & 7.2 & 3.9 & 3.3 & 45.8 \\
\hline 50 & 19.1 & 27.5 & 8.4 & 44.0 & 11.2 & 6.1 & 5.1 & 45.5 \\
\hline 51 & 13.3 & 20.7 & 7.4 & 55.6 & 9.8 & 4.5 & 5.3 & 54.1 \\
\hline 52 & 20.5 & 25.7 & 5.2 & 25.4 & 12.2 & 9.1 & 3.1 & 25.4 \\
\hline 53 & 17.0 & 21.7 & 4.7 & 27.6 & 16.7 & 14.0 & 2.7 & 16.2 \\
\hline 54 & 17.8 & 20.8 & 3.0 & 16.9 & 21.5 & 18.9 & 2.6 & 12.1 \\
\hline 55 & 16.8 & 17.4 & 0.6 & 3.6 & 6.3 & 5.7 & 0.6 & 9.5 \\
\hline 56 & 13.9 & 21.3 & 7.4 & 53.2 & 16.0 & 7.4 & 8.6 & 53.8 \\
\hline 57 & 16.4 & 19.3 & 2.9 & 17.7 & 11.9 & 9.9 & 2.0 & 16.8 \\
\hline 58 & 20.8 & 23.0 & 2.2 & 10.6 & 5.3 & 1.9 & 3.4 & 64.2 \\
\hline 59 & 10.7 & 15.0 & 4.3 & 40.2 & 18.4 & 13.1 & 5.3 & 28.8 \\
\hline 60 & 17.9 & 20.0 & 2.1 & 11.7 & 1.6 & 0.4 & 1.2 & 75.0 \\
\hline 61 & 17.7 & 20.3 & 2.6 & 14.7 & 9.7 & 7.0 & 2.7 & 27.8 \\
\hline
\end{tabular}

is reduced at high cement viscosity injection. The targeting delivery of a highly viscous cement in the anterior third of a compressed vertebral body has been reported to result in height restoration of VCFs [12-14].

Our study results of RF kyphoplasty demonstrate a significant pain relief in all consecutive follow-up interval periods. A significant back pain and function ODI $(p<0.001)$ was achieved immediately postoperatively and in both 6-month and 1-year follow-up. Compared to other studies of vertebroplasty, balloon kyphoplasty, and RF kyphoplasty, we observed no difference in pain relief between different methods of vertebral augmentation techniques [15-18].

In our study, we measured the kyphotic angle and mean vertebral height. The mean local kyphotic angle was $9.04^{\circ}$ preoperatively which decreased to a mean of $6.16^{\circ}$ postoperatively with $62 \%$ of fractures restored more than $2^{\circ}$. The mean vertebral height was $19.16 \mathrm{~mm}$ preoperatively and increased to $22.50 \mathrm{~mm}$ postoperatively. Sixty percent of fractures increased more than $2 \mathrm{~mm}$ in height postoperatively.

In our study, the mean vertebral body height increased by $3.34 \mathrm{~mm}$ and mean local kyphotic angle decreased by $2.88^{\circ}$, comparable to both balloon kyphoplasty and vertebroplasty.

Pflugmacher et al. [12] showed that the average increase in the middle part of the vertebral bodies in both RF kyphoplasty and balloon kyphoplasty was $3.1 \mathrm{~mm}$. Previous work has shown that the average decrease in kyphosis angle is $4.4^{\circ}$ in RF kyphoplasty, and balloon kyphoplasty decreases kyphosis by $3.8^{\circ}$; the results of both methods are comparable to ours. The difference in height restoration and local kyphotic angle between the three techniques is generally small [16-18].

The Wilcoxon rank sum test revealed that mean local kyphotic angle and mean vertebral height were success- 
fully achieved $(p<0.001)$

This RF kyphoplasty procedure provides a unique level of control which addresses the problem of cement leakage due to the combination of controlled delivery of RFactivated (high viscosity) cement at a fixed, low rate of delivery into site-specific channels created using a navigational osteotome. Additionally, based on the unipedicular access. Accordingly, this controlled procedure of remotely controlled cement delivery RF kyphoplasty may decrease procedural invasiveness and cement leakage $[12,14]$.

Our study observed five cases of cement leakage (8\%). Yeom et al. [10] observed 74 leaks in 48 osteoporotic vertebral fractures [OVFs] treated by vertebroplasty. Our results are far less compared to vertebroplasty (38\%-72.5\%) [19].

Our results are comparable to other balloon kyphoplasty and RF kyphoplasty studies. Schulz et al. [20] showed cement leakage in eight out of 46 OVFs treated by balloon kyphoplasty (17.4\%). Cement leakage incidence in RF kyphoplasty is less than $50 \%$ compared with balloon kyphoplasty [8].

\section{Conclusions}

RF kyphoplasty is the newest vertebral augmentation procedure consisting of delivery of ultrahigh viscosity cement activated by RF energy to control cement consistency and minimize cement leakage. It is a good alternative for the treatment of VCFs.

\section{Conflict of Interest}

No potential conflict of interest relevant to this article was reported.

\section{References}

1. Johnell O, Kanis JA. An estimate of the worldwide prevalence and disability associated with osteoporotic fractures. Osteoporos Int 2006;17:1726-33.

2. Rzewuska M, Ferreira M, McLachlan AJ, Machado GC, Maher CG. The efficacy of conservative treatment of osteoporotic compression fractures on acute pain relief: a systematic review with meta-analysis. Eur Spine J 2015;24:702-14.

3. Feltes C, Fountas KN, Machinis T, et al. Immediate and early postoperative pain relief after kyphoplasty without significant restoration of vertebral body height in acute osteoporotic vertebral fractures. Neurosurg Focus 2005;18:e5.

4. Cloft HJ, Jensen ME. Kyphoplasty: an assessment of a new technology. AJNR Am J Neuroradiol 2007;28:200-3.

5. La Maida GA, Giarratana LS, Acerbi A, Ferrari V, Mineo GV, Misaggi B. Cement leakage: safety of minimally invasive surgical techniques in the treatment of multiple myeloma vertebral lesions. Eur Spine J 2012;21:S61-8.

6. Choe DH, Marom EM, Ahrar K, Truong MT, Madewell JE. Pulmonary embolism of polymethyl methacrylate during percutaneous vertebroplasty and kyphoplasty. AJR Am J Roentgenol 2004;183:1097102.

7. Al-Nakshabandi NA. Percutaneous vertebroplasty complications. Ann Saudi Med 2011;31:294-7.

8. Dalton BE, Kohm AC, Miller LE, Block JE, Poser RD. Radiofrequency-targeted vertebral augmentation versus traditional balloon kyphoplasty: radiographic and morphologic outcomes of an ex vivo biomechanical pilot study. Clin Interv Aging 2012;7:525-31.

9. Alanay A, Pekmezci M, Karaeminogullari O, et al. Radiographic measurement of the sagittal plane deformity in patients with osteoporotic spinal fractures evaluation of intrinsic error. Eur Spine J 2007;16:2126-32.

10. Yeom JS, Kim WJ, Choy WS, Lee CK, Chang BS, Kang JW. Leakage of cement in percutaneous transpedicular vertebroplasty for painful osteoporotic compression fractures. J Bone Joint Surg Br 2003;85:83-9.

11. Cooper C, Atkinson EJ, Jacobsen SJ, O'Fallon WM, Melton LJ 3rd. Population-based study of survival after osteoporotic fractures. Am J Epidemiol 1993;137:1001-5.

12. Pflugmacher R, Bornemann R, Koch EM, et al. Comparison of clinical and radiological data in the treatment of patients with osteoporotic vertebral compression fractures using radiofrequency kyphoplasty or balloon kyphoplasty. Z Orthop Unfall 2012;150:56-61.

13. Elgeti F, Gebauer B. Radiofrequency kyphoplasty for the treatment of osteoporotic and neoplastic vertebral body fractures: preliminary experience and clinical results after 6 months. J Miner Stoffwechs 
2011;18(Suppl 1):5-9.

14. Bornemann R, Kabir K, Otten LA, et al. Radiofrequency kyphoplasty: an innovative method for the treatment of vertebral compression fractures: comparison with conservative treatment. Z Orthop Unfall 2012;150:392-6.

15. Georgy BA. Comparison between radiofrequency targeted vertebral augmentation and balloon kyphoplasty in the treatment of vertebral compression fractures: addressing factors that affect cement extravasation and distribution. Pain Physician 2013;16:E513-8.

16. Hiwatashi A, Westesson PL, Yoshiura T, et al. Kyphoplasty and vertebroplasty produce the same degree of height restoration. AJNR Am J Neuroradiol 2009;30:669-73.
17. Ledlie JT, Renfro M. Balloon kyphoplasty: one-year outcomes in vertebral body height restoration, chronic pain, and activity levels. J Neurosurg 2003;98:3642.

18. Teng MM, Wei CJ, Wei LC, et al. Kyphosis correction and height restoration effects of percutaneous vertebroplasty. AJNR Am J Neuroradiol 2003;24:1893900.

19. Martin DJ, Rad AE, Kallmes DF. Prevalence of extravertebral cement leakage after vertebroplasty: procedural documentation versus CT detection. Acta Radiol 2012;53:569-72.

20. Schulz C, Efinger K, Schwarz W, Mauer UM. Experiences with cement leakage after balloon kyphoplasty. Orthopade 2012;41:881-8. 